\title{
Computer training in psychology at the University of Colorado
}

\author{
DANIEL E. BAILEY \\ University of Colorado, Boulder, Colorado 80302
}

The purpose of this paper is to describe the University of Colorado training program in real-time and on-line computing. The program is perhaps best understood in the context of the overall programs of the Departments of Computer Science and Psychology.

The curricular organization is schematically presented in Fig. 1.

\section{THE DEPARTMENT OF PSYCHOLOGY}

The undergraduate program in the Department of Psychology at the University of Colorado is organized around a three-track scheme that permits the major to "specialize" in socio-clinical, experimental-behavioral, or bio-animal psychology. A number of upper division courses have formal laboratories in which student "research" projects are assigned for execution in the laboratory.

The faculty of the Department of Psychology is 47 in number, and is composed of six subgroups associated with the six doctoral programs of the department: experimental, social, quantitative, developmental, clinical, and biopsychology. The quantitative psychology program provides the faculty members who teach computer-related materials.

The quantitative psychology program operates a department-wide computer laboratory. the Computer Laboratory for Instruction in Psychological Research, CLIPR, for instruction in computer use, on-line research, and for development of the computer as a teaching aid in the department. The computer in this laboratory is available for use by all members of the psychology faculty and graduate student body without charge. Certain undergraduate students. particularly those taking certain courses, use the computer in the psychology computer lab-also without charge. There currently are three members of the quantitative faculty who teach computer programming and high-level technical courses in computer usage and computer theory

\section{THE DEPARTMENT OF COMPUTER SCIENCE}

The Department of Computer Science offers both master's and doctoral degrees. but no undergraduate degree. The areas of expertise represented in the department are three in number: numerical analysis. automata theory. and software systems. The department offers several courses of direct relevance to on-line computing. including both hardware and software topics. A number of the faculty members are interested in. and willing to teach courses relevant to, areas in the social and behavioral sciences, the humanities, and allied fields.

Undergraduate courses are offered in basic computer science, with specialization of the introductory course into three sections: mathematical sciences and engineering, business, and the social and behavioral sciences and humanities. Second-level (junior and senior students) courses are offered in these same three areas. Undergraduates may present a distributed major for graduation-including computer science.

\section{TYPES OF COMPUTING ACTIVITIES IN PSYCHOLOGY INSTRUCTION}

There are several separate types of computing activity available to students in the instructional programs of the Department of Psychology. Two of these activities are supported out of funds of the Department of Computer Science, the rest are supported within the Department of Psychology.

\section{General Computer Science Courses}

Two courses offered by the Department of Computer Science are of significant interest to the Department of Psychology for undergraduate education: Computer Science 203 and Computer Science 313. Computer Science 203 is a general course at the sophomore level aimed at students in the arts and science curriculum but not engaged in the study of the hard sciences or technological fields. Students in the social and behavioral sciences and the humanities are singled out in the course title. The course is virtually identical to the two sections of the 200-level course aimed at students in engineering and the hard sciences. However, the motivating examples and problems assigned for solution are taken from subject matter of the major fields of the students in the class. The topics covered are: introduction to algorithms and computer $(3 \mathrm{~h})$; flow charting and introduction to FORTRAN IV $(6 \mathrm{~h})$; FORTRAN input and output rudiments $(3 \mathrm{~h})$; FORTRAN: declarations, control. logical $(3 \mathrm{~h})$; FORTRAN : control. logical, looping ( $3 \mathrm{~h}$ ); FORTRAN: more on input and output $(3 \mathrm{~h})$; FORTRAN: subroutines. functions, and procedures $(3 \mathrm{~h})$; programming and operating systems. compiling $(3 \mathrm{~h})$; numerical approximations $(3 \mathrm{~h})$; trees and branching processes $(6 \mathrm{~h})$ : lists and strings $(3 \mathrm{~h})$; computer simulation of natural processes $(3 \mathrm{~h})$ : and real-time, on-line computers $(6 \mathrm{~h})$.

In addition to attending three 50 -min lectures, the students meet with a teaching assistant for a $2 \cdot \mathrm{h}$ "recitation." These recitations are small group meetings with 15 or fewer students. The recitation period is 


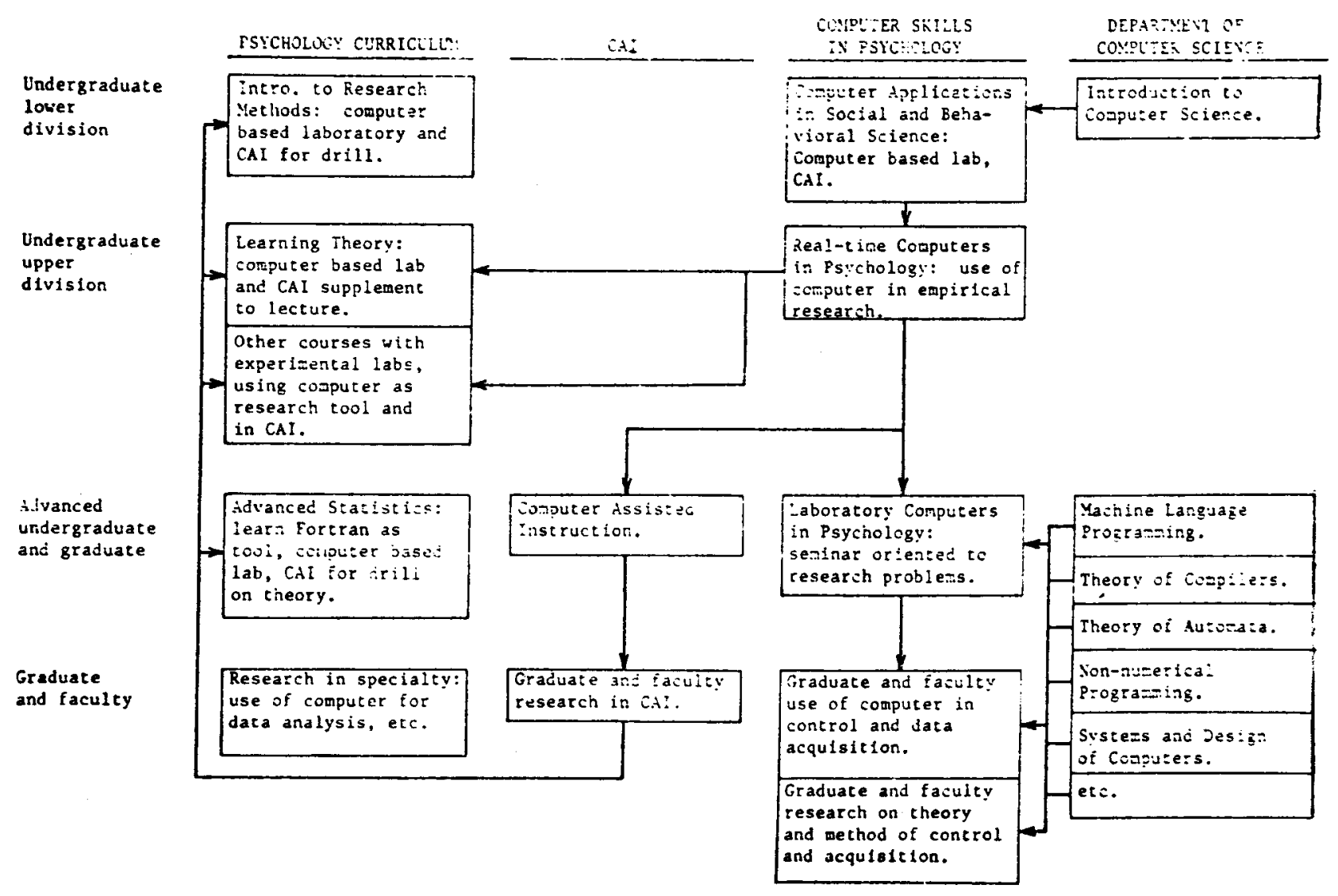

Fig. 1. Curricular organization in the CLIPR Project.

devoted to developing skill in programming and to presentation of problems and assignments to the students. Each student executes a number of programming projects, all in FORTRAN. This course and Computing Science 313 are used as recruiting vehicles to attract students into on-line, real-time courses offered in psychology. Six hours of lecture introduce the concepts of and applications of real-time, on-line computing.

Computing Science 313 is designed to be a second course for students in the arts and sciences disciplines. It presumes programming and computer knowledge at the level of the students completing Computer Science 203. The topics covered are: matrices and vectors $(3 \mathrm{~h})$; statistical computations $(3 \mathrm{~h})$; branching processes and graphs $(3 \mathrm{~h})$; lists and list processing (SNOBOL4) $(6 \mathrm{~h})$; random processes (Monte Carlo techniques) ( $3 \mathrm{~h}$ ); simulation techniques $(3 \mathrm{~h})$; large-scale file structures $(6 \mathrm{~h})$; models of large-scale systems $(3 \mathrm{~h})$; analysis of textual materials $(3 \mathrm{~h})$; real-time computers $(3 \mathrm{~h})$; computer-assisted instruction $(3 \mathrm{~h})$; computer-controlled laboratories ( $3 \mathrm{~h})$; computer collection of data $(3 \mathrm{~h})$ : and analog input to digital computers $(3 \mathrm{~h})$.

The emphasis of the course is on programming and use of the computer rather than on substantive problems and issues. The students learn SNOBOL4 as a second programming language. Approximately 5 weeks of instruction in on-line. real-time computing is presented.
Some actual experience in real-time nrogramming is gained by the students.

\section{Specialized Computer Science Courses}

A variety of upper division and graduate-level courses in computer science are utilized by the students in psychology. These courses range from purely technical courses such as Assembly language programming to highly content-oriented courses.such as computer-based decision modeling. In large part, the impact of the specialized computer science courses is transmitted to the undergraduate program in psychology through graduate students in psychology. A number of psychology graduate students pursue the master's degree in computer science concurrently with their work on the $\mathrm{PhD}$ degree in psychology. These students frequently serve as assistants in the courses offered in psychology that involve computer applications.

\section{Specialized Psychology Courses}

Five courses in psychology are designed around computer utilization. One of these five courses is cross-listed with Computer Science 313. already described. This course is listed in both course schedules only when the faculty member serving in both departments teaches the course. It is possible for psychology-major students to offer this course as a part of his elective courses for the major. 
Psychology 403. "Real-time Computers in Psychology," is a junior-/senior-level course covering the use of real-time computer applications in psychological research. The students are taught a special-purpose, high-level, language called the State Change Algorithm Translator, SCAT. They execute a number of projects on the CLIPR real-time computer. The course is designed to get undergraduate students immediately and effectively on the computer system for execution of empirical research. The students work "hands-on" with the computer and terminal research equipment. The major portion of the course is devoted to programming instruction. However, a number of major research paradigms in psychology are covered, and projects in these paradigms are executed by the students. Students in the course are assumed to have had an introduction to computer programming, either through a computer science course or a laboratory course in psychology that includes introductory programming.

Psychology 403 covers the following subjects: SCAT programming $(15 \mathrm{~h})$; SCAT operating system ( $3 \mathrm{~h})$; operant conditioning experiments $(3 \mathrm{~h})$; probability learning, serial pattern learning $(3 \mathrm{~h})$; Sternberg high-speed memory search paradigm $(3 \mathrm{~h})$; data structures, data management, and data reduction $(3 \mathrm{~h})$; principles of stimulus presentation $(3 \mathrm{~h})$; concept identification ( $3 \mathrm{~h})$; stimulus structures $(3 \mathrm{~h})$; running Ss concurrently, group problem solving (3h): paired-associates learning $(3 \mathrm{~h})$; and manipulation of character codes $(3 \mathrm{~h})$.

Psychology 503, "Seminar: Laboratory Computers in Psychology," is a course open to advanced undergraduate and graduate students. This course is intended largely as a training forum for psychology students desiring to make professional-level use of the CLIPR computer facilities in their research. The course assumes that the students are competent FORTRAN programmers. An emphasis on actual use of the computer for research is characteristic of the course. The students are expected to design and execute a full-scale real-time computer project within the one semester of the course. A good deal of the semester is devoted to student reports of their proposals and then of their final project status at the end of the semester. All work is done through the CLIPR real-time FORTRAN software. No Assembly language programming is taught. However. students in this course often are engaged in computer science master's degree programs and do a certain amount of this work in Assembly.

The course outline. other than the student reports. includes: state change algorithm translator $(4 \mathrm{~h})$ : FORTRAN real-time interface software $(9 \mathrm{~h})$ : character-oriented $\mathrm{I} / \mathrm{O}$ real-time work $(3 \mathrm{~h})$ : disk $\mathrm{I} / \mathrm{O}$ $(3 \mathrm{~h})$ : illustrations of real-time projects $(3 \mathrm{~h})$ : computer architecture and software $(3 h)$ : and computer laboratories with small computers $(3 \mathrm{~h})$.

Psychology 682. "Computer-Assisted Instruction." is a graduate-level seminar oriented to the development of computer-assisted instruction techniques and facilities. The seminar is devoted only in a preliminary handful of sessions to the study of published literature on CAI. It is assumed that the students in the seminar have at least an intermediate level of skill in FORTRAN programming. The emphasis is on development of software and courses of instruction.

Psychology 593, "Proseminar in Quantitative Psychology." is a graduate-level course taught for one-half a semester for students in the quantitative psychology graduate program and students in other graduate psychology programs who wish to "minor" in quantitative psychology. Four sections of this course are taught, only one of which is computer-oriented. The computer-oriented section is an advanced version of Computer Science 313, covering the topics of that course in more depth and with greater speed. The students are expected to be largely self-sufficient in their reading.

\section{Use of Computers in Course Laboratories}

A number of courses use the computer as an adjunct to the primary subject matter of the course. Only two such courses are discussed here, the undergraduate research methods course and the graduate-level statistics course. Psychology 210, "Introduction to Research Methods," is devoted primarily to training sophomore-level psychology majors in statistics and research methods. It is a required course and is taught in several sections by different instructors. The common denominator of all sections is coverage of elementary statistics. The distinguishing feature of one section is the computer orientation of the associated laboratory work. Each student attends $2 \mathrm{~h}$ of laboratory each week, during which he learns two ways in which the computer can be of use as a research tool. The students are taught FORTRAN, and are expected to write simple programs dealing with statistical problems. In addition, more complex statistical problems are confronted by the students using the CLIPR statistical program packages.

Psychology 587.588, "General Statistics," is a two-semester graduate-level course in statistics. During the first semester, the lecture portion of the course is addressed to probability and distribution theory with an introduction of statistical decision theory. The laboratory portion of the course during the first semester is devoted to FORTRAN programming. The semester provides $32 \mathrm{~h}$ of laboratory time. during which the entire range of FORTRAN and a few applications of FORTRAN are covered. The students are assigned about 10 small programming projects and a more ambitious term project of their own design or from a list of projects provided by the instructor. The second-semester lecture portion of the course is devoted to applications of statistical decision theory. The laboratory portion of the course parallels the lecture portion in use of canned programs and in the assignment of programming problems. The students execute a second major programming project during the second semester. 